\title{
EXPLORING THE OPPORTUNITIES FOR IMPLEMENTING INNOVATIVE IDEAS AMONG YOUNG ENTREPRENEURS
}

\author{
Siyka Demirova ${ }^{278}$ \\ Sibel Ahmedova ${ }^{279}$
}

https://doi.org/10.31410/itema.2018.773

\begin{abstract}
Every fast-growing economy is identified by its innovative businesses and everexpanding markets. A vital prerequisite for the development of innovation and creation of a higher value-added economy is the provision and encouragement of independent economic activity. Enhancing entrepreneurial mindsets, skills and attitudes of young people is associated with innovation and risk-taking and is forms an integral part of a country's ability to prosper in a rapidly changing and highly competitive market. In light of this, the purpose of the present paper is to explore and analyze the opportunities for implementing innovative ideas among young entrepreneurs. The results of the research study will help identify the main problems and significant challenges young entrepreneurs are likely to encounter.
\end{abstract}

Keywords: innovative ideas, young entrepreneurs, highly competitive market

\section{INTRODUCTION}

Y outh entrepreneurship is one of the most promising areas of economic development of every country, which is, in fact, the potential for its development. Naturally, its decisive role and fundamental importance have been presently under very active discussion amongst the respective government, business and scientific communities [1], [2], [3].

In Bulgaria, the problem is not so much the lack of entrepreneurial mindset of the young people, but the lack of prospective field for entrepreneurial activities and realization of their internal capacities and potential. The toughest issue young people who want to develop as entrepreneurs face today, even at the very beginning, refers to the type of the entrepreneurial endeavor they might venture into [4], [5], [6].

Part of the long-term issues a large number of EU member states currently face are the inefficiently functioning link between education and the labour market, the high proportion of inactive young people and the need for reforms in the area of youth employment [7]. The relative share of youth unemployment in the EU has increased from $15 \%$ in 2008 to $24 \%$ at the very beginning of 2018. The EU statistics show that the rate of youth unemployment in Greece is $60 \%$, in Spain - 56,2\%, Croatia - 49,8\%, Italy - 44\% and Portugal - 40,7\%. More than 40\% of young people in the European Union prefer to be self-employed individuals rather than employees working under a contract of employment. And yet, the reported success rate in 2016 was only $4,1 \%$, which represents one third of the proportion of all self-employed persons aged $15-64$ years $[8]$.

\footnotetext{
278 Technical University of Varna, 1 Studentska Str., Varna, Bulgaria

${ }^{279}$ Technical University of Varna, 1 Studentska Str., Varna, Bulgaria
} 
Regardless of the fact that the statistical data on youth unemployment rate and the percentage of inactive young people have generated a lot of discussion at the European and national levels, the research effort should nevertheless focus on the analysis and evaluation of the opportunities for the implementation of creative business ideas among young entrepreneurs [9],[10],[11].

\section{RESEARCH INTO THE OPPORTUNITIES FOR IMPLEMENTATION OF INNOVATIVE IDEAS AMONG YOUNG ENTREPRENEURS}

Encouraging active support for the start-ups in the European Union would advance the development of young talents, which, in turn, would ensure the creation of high levels of added value [12]. Approximately 2000 startups have been established over the past five years. Due to the measures adopted by the country, this number is expected to double in 2019.

Surveyed, for the purposes of the present research study, were 90 most responsive attendees at the Techstars Startup Weekend organized by the TU-Varna "Entrepreneurship Club". The anonymous survey contained 10 thematically grouped questions designed to explore the opportunities for implementing innovative ideas among young entrepreneurs. The respondent young entrepreneurs fall into the 20-24 age group. An additional research tool that adds extra support to the survey responses is the on-site interview. Thus, the overall survey responses tend to be more concrete, genuine and highly reliable.

The results of the survey show that $15 \%$ of the respondents have undertaken a thorough investigation and analysis of the entrepreneurial environment in Bulgaria at the macroeconomic level, and $12 \%$ - at the microeconomic level. The lower relative proportion is predetermined by the lack of sufficient knowledge and by the complexity of the research and analysis of the business environment in our country. $36 \%$ of young entrepreneurs have made some inquiries into the opportunities for starting a business training courses, $25 \%$ of them - into the available traineeship opportunities and $22 \%$ - into the practical opportunities to start their own business. $35 \%$ of the respondents state that they are well-informed about the organizations promoting entrepreneurship activities and suggest, further, that more concrete initiatives and specific measures should be taken in order to encourage and foster youth entrepreneurship. $98 \%$ of the respondents propose the initiation of local mentoring programs with the active participation of experienced, skillful and knowledgeable people, 92\% - the provision of (free) training, legal and administrative assistance, $89 \%$ - the establishment of a scholarship fund for young scientists, enabling them to commercialize their scientific discoveries, $85 \%$ - the procurement of free/subsidized advisory and consulting services for business development and/or successful application for European and national programs, 82\% - simplification of administrative procedures and $75 \%$ - introduction of tax incentives for start-up ventures. In addition, $96 \%$ of the participants surveyed maintain that organizing a Startup Weekend would be extremely helpful for the development of entrepreneurial skills among young people.

Young entrepreneurs have conclusively identified the most common barriers they repeatedly face: uncertainty in decision-making, lack of financial resources, business ideas and entrepreneurial skills, fear of failure and the general economic climate in the country, as shown in Figure 1. 
Figure 1: Barriers to Young Entrepreneurs

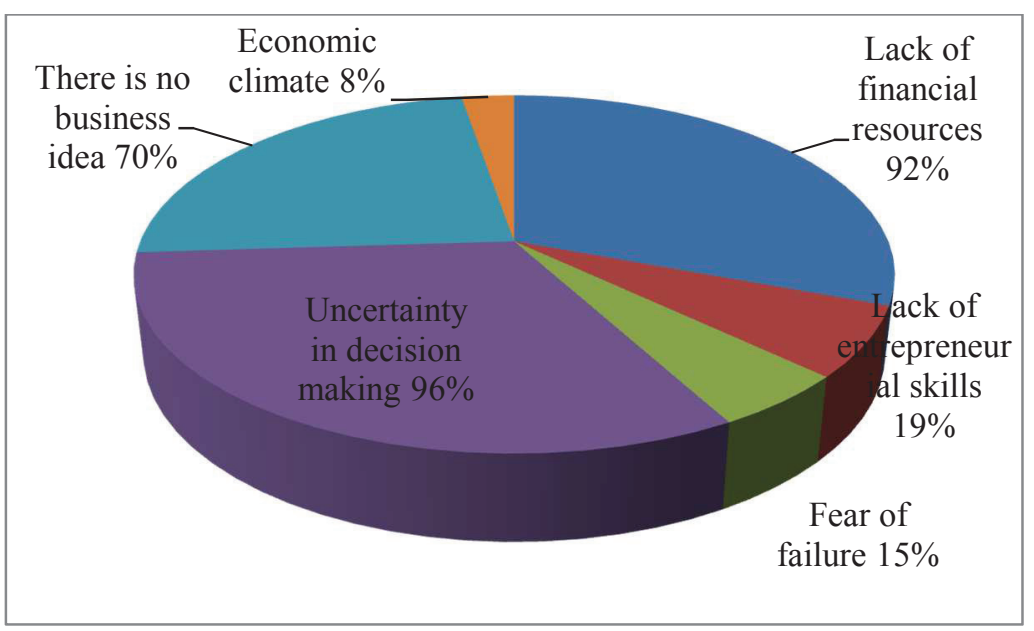

Figure 2 describes the respondents' answers to the question: "What concrete actions should be taken to adapt the higher education so as to ensure equal opportunities for the implementation of innovative ideas?". 89\% of the respondents claim that organizing periodic Startup Weekend would give them the opportunity to put their innovative ideas into practice. What's more, $85 \%$ of young entrepreneurs specify that organizing meetings between students and businesses will contribute to the adaptation of their educational course syllabi to the requirements of today's employers. The student-business meetings would, in turn, allow for the provision of traineeships (73\%), participation in business incubator projects $(15 \%)$ and technology transfer processes $(38 \%)$.

Figure 2: Actions for adapting the education of students

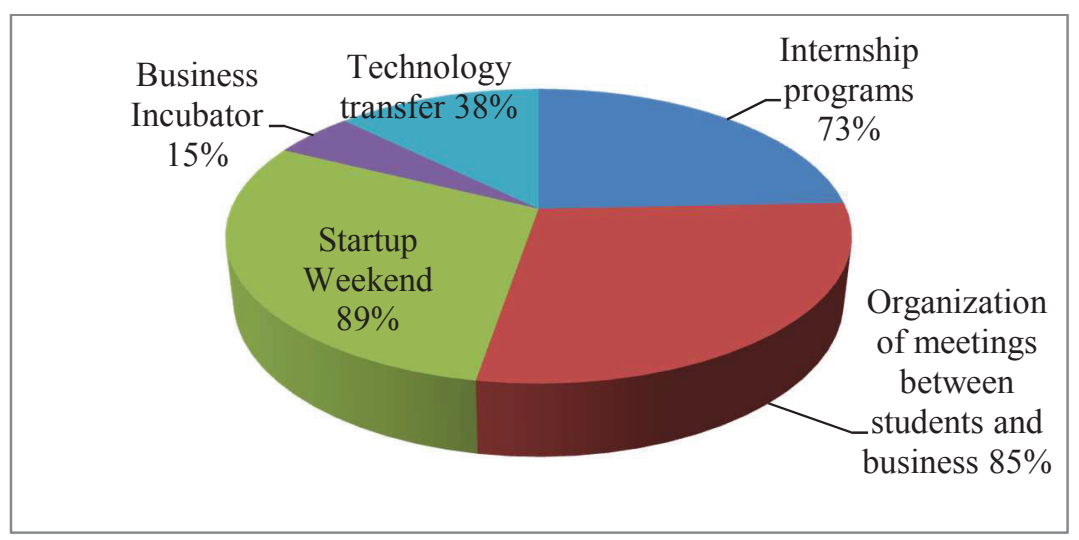

As for the key factors that affect the practical implementation of innovative ideas, the young entrepreneurs give prominence to: the availability of financial resources - 97\%; good management and contact with the right people - 95\%; technology - 93\% and simplified administrative procedures $-91 \%$. The respondents consider the following possibilities of funding their innovative ideas: project funding - 95\%; bank lending - 85\%; non-traditional sources of startup financing such as business angels $-59 \%$ and venture capital funds $-33 \%$. All in all, the young entrepreneurs are more likely to turn to traditional sources of financing, and the reason is mainly because of the less complicated and easier lending procedures.

As for the implementation of their innovative ideas, the young entrepreneurs believe that the access to the sources of startup financing should be improved and the burden of administrative 
procedures placed on startups should be reduced. Of equal importance are such prospects as the direct involvement and active participation of young people in initiatives that contribute to the implementation of innovative ideas, development of creativity and knowledge of the methods for generating new ideas through formal and informal training activities, which is shown in Figure 3.

Figure 3: Measures for the implementation of innovative ideas

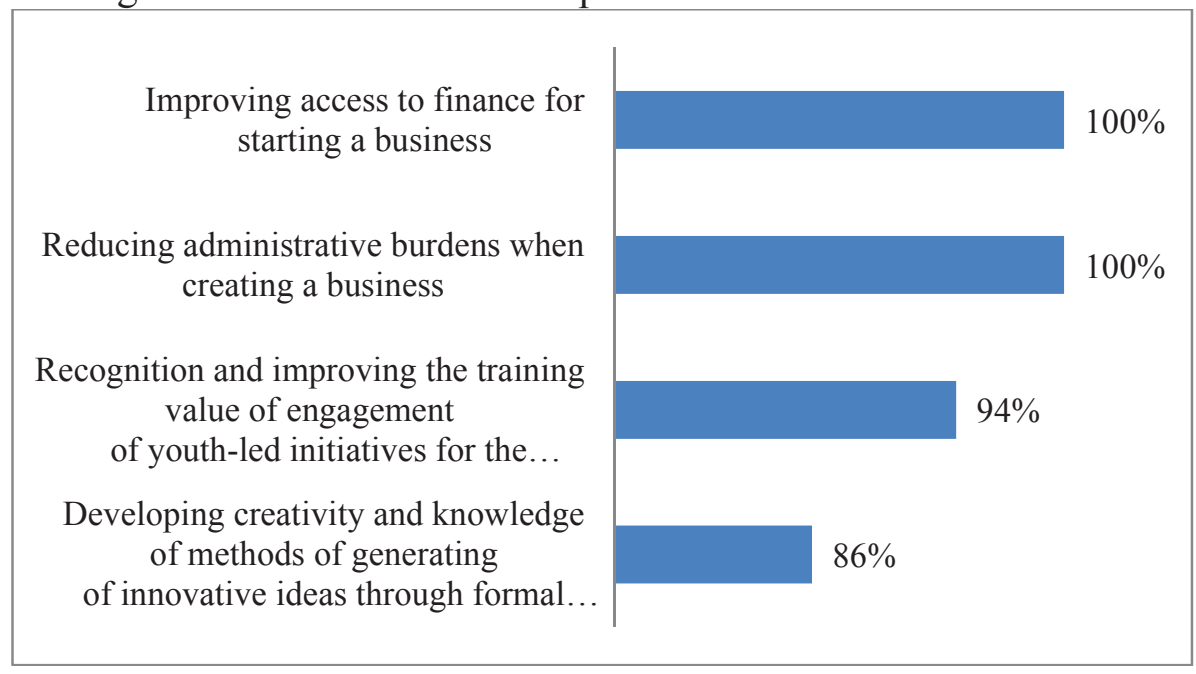

Moreover, the surveyed students also point out that the main factors influencing the practical implementation of innovative ideas are financial resources, good management, establishing contacts with the right people, simplified administrative procedures and access to technologies, as shown in Figure 4. 97\% of young entrepreneurs face difficulties in the practical implementation of their innovative ideas. The inability to finance innovative ideas is the result of the high credit evaluation and approval requirements that most of the respondents do not meet. Besides, the lack of financial resources has a strong impact on the access to technology. Lengthy administrative procedures prove to be a serious impediment that prevents the easy implementation of innovative ideas. Entrepreneurs are required to complete a number of documents when applying for funding, and if they fail to meet a certain standard, their project is rejected. To avoid such an option, the respondents may hire special consultants, which, in turn, lead to an increase in the cost of project implementation.

Figure 4: Factors influencing the practical implementation of innovative ideas

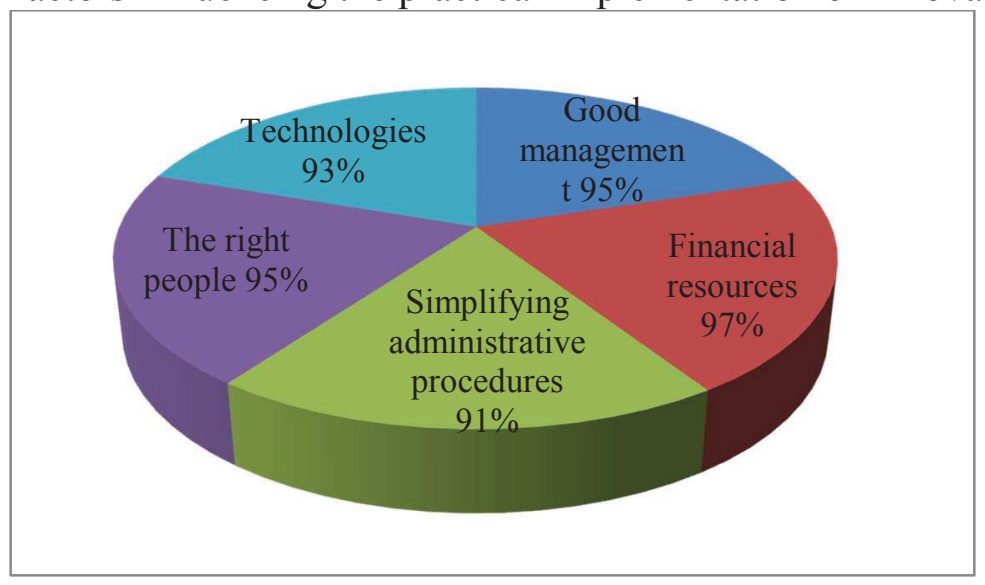


As their main advantages, the young entrepreneurs focus on: less responsibilities - 95\%; a high degree of activity $-85 \%$; more free time $-80 \%$; youth naivety $-70 \%$; willingness to experiment $-65 \%$.

Figure 5: Advantages of young people in the implementation of innovative ideas

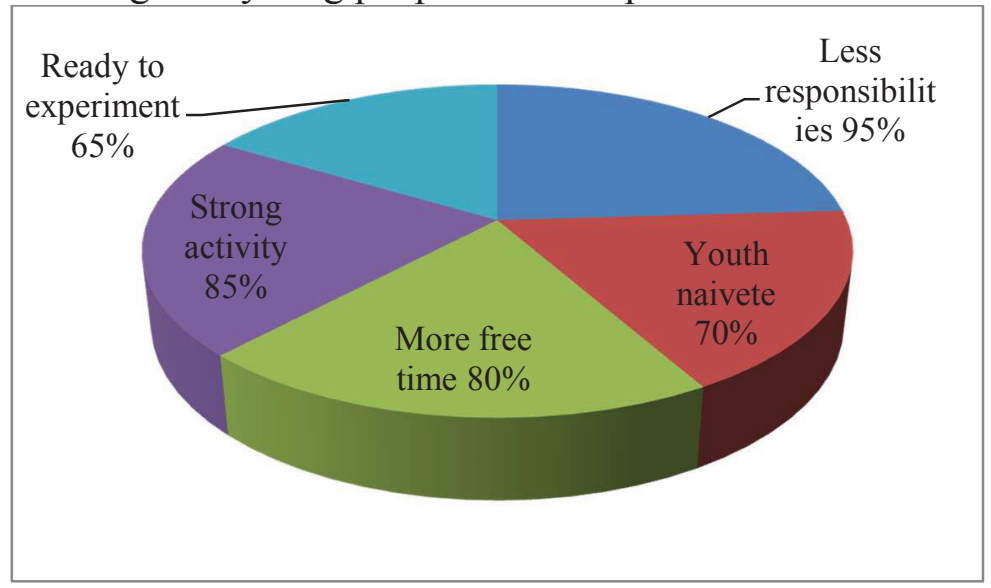

Young entrepreneurs are always ready to do and learn new things. Such eagerness is a considerable advantage especially if it is harnessed effectively and projected in the right direction. Unwillingness to take on greater responsibilities and the availability of ample time for leisure activities is often a prerequisite for the discernible expression of increased activity, which is verified by the high percentage of the responses $-85 \%$. Thus, they proved to be more flexible, more creative, more dedicated and committed to their pursuits. Contrary to expectations, naivety can also be a great advantage because it allows the young entrepreneur to explore new ways and practices to keep ahead of the severe competition, as shown in Figure 5.

\section{CONCLUSION}

Reached, on the basis of the results obtained from the conducted research study into the opportunities for implementing innovative ideas among young entrepreneurs, are the following principal conclusions (key findings):

- Reached is the conclusion that the respondents encountered difficulties in exploring and analyzing the entrepreneurial environment in Bulgaria due to the lack of sufficient knowledge and skills;

- Proposed, as a result of the survey, are specific concrete measures to help promote youth entrepreneurial activity;

- Identified are the main barriers faced by young entrepreneurs, namely, uncertainty in decision-making and lack of financial resources;

- Distinguished are the factors influencing the practical implementation of innovative ideas among young entrepreneurs.

- Determined are the main problems faced by the young entrepreneurs in implementing their innovative ideas.

- Summarized, on the basis of the survey/interview questions, are the measures to be taken towards successful implementation of innovative ideas. 


\section{REFERENCES}

[1] Cheolwoo Park, (2016) A study on effect of entrepreneurship on entrepreneurial intention: Focusing on ICT majors, Asia pacific journal of innovation and entrepreneurship, Volume 11 , Issue 2

[2] Olugbola, S., A., (2017) Exploring entrepreneurial readiness of youth and startup success components: Entrepreneurship training as a moderator, Journal of Innovation \& Knowledge, Volume 2, Issue 3, pp. 155-171

[3] Jeffrey H. Dyer, Hal B. Gregersen, Clayton Christensen (2009) Entrepreneur behaviors, opportunity recognition, and the origins of innovative ventures, Strategic Entrepreneurship Journal, Volume 2, Issue 4

[4] Demirova S., (2013) Innovation development and innovation policy of small and mediumsized industrial enterprises, ed. Color Print, Varna

[5] Petkova - Georgieva S., Karadhova Z., (2016) The scientific and technological parks as part of the innovation networks - the environment to create knowledge and increase innovation as a result of study by relationship, International Scientific Conference "Economic Welfare through Sharing Knowledge", pp.186-191

[6] Todorov K., (2011) Business entrepreneurship, I and II part, BAMDE, Sofia

[7] OECD, (2014) Supporting Youth in Entrepreneurship, Summary report of a policy development seminar organized by the OECD and the European Commission, Brussels

[8] European Union, (2016) Young and innovative: how to help young entrepreneurs be more innovative?, Ref. Ares 6361498 - 10/11/2016

[9] Giustina Secundo, Pasquale Del Vecchio, Giovanni Schiuma and Giuseppina Passiante, (2017) Activating entrepreneurial learning processes for transforming university students' idea into entrepreneurial practices, International Journal of Entrepreneurial Behavior \& Research, 23, 3

[10] Krastina A., (2014) Support - A Vital Tool for Young Innovative Entrepreneurs in the Barents Region, ENPI Kolarctic "Young Innovative Entrepreneurs" project study

[11] Ji Young Kim, Dae Soo Choi, Chang-Soo Sung and Joo Y. Park, (2018) The role of problem solving ability on innovative behavior and opportunity recognition in university students, Journal of Open Innovation: Technology, Market and Complexity, Volume 4, Issue 1

[12] European Union, (2015) Unleashing young people's creativity and innovation, report 